\title{
SISTEM PAKAR IDENTIFIKASI JENIS KULIT WAJAH MANUSIA UNTUK MENENTUKAN PERAWATAN FACIAL KECANTIKAN MENGGUNAKAN METODE FORWARD CHAINING
}

\section{PUTRI EKOWATI}

Teknik Informatika, Fakultas Teknik Universitas Maarif Hasyim Latif, Sidoarjo, Indonesia e-mail : putri-ekowati@student.umaha.ac.id

\section{ABSTRAK}

Kulit wajah membutuhkan perawatan yang teratur karena sangat sensitif, mudah iritasi, meradang, berjerawat dan masih banyak lagi kondisi kulit lainnya. Tujuan pembuatan aplikasi ini untuk merancang dan membuat sistem pakar yang mampu mengidentifikasi jenis kulit wajah untuk menentukan perawatan facial kecantikan berbasis Android jadi sangat membantu memudahkan user menentukan perawatan facial wajah tanpa harus mengantri dan menunggu konsultasi dengan dokter kecantikan ataupun mendadak dokter sedang tidak bisa praktek, sehingga bisa digunakan mengetahui jenis perawatan facial kulit wajah.

Kata kunci : forward chaining, perawatan facial wajah, sistem pakar, android

\section{PENDAHULUAN}

Sistem pakar menurut Marimin [1] ialah sistem perangkat lunak komputer yang menggunakan ilmu, fakta dan teknik berpikir dalam pengambilan keputusan untuk menyelesaikan masalah biasanya dapat diselesaikan oleh tenaga ahli dalam bidang yang bersangkutan.

Perancangan sistem pakar dibuat berbasis Android tentunya lebih praktis dan akan lebih memudahkan admin di tempat klinik kecantikan dalam menentukan perawatan facial wajah dengan mengidentifikasi jenis kulit wajah tanpa harus mengantri dan menunggu dokter kecantikan ataupun mendadak dokter sedang tidak bisa praktek, sehingga bisa digunakan mengetahui perawatan facial wajah yang sesuai sehingga membantu mengidentifikasi secara cepat.

\section{METODOLOGI PENELITIAN}

\section{Perencanaan Sistem}

Sistem pakar digunakan menyelesaikan suatu pilihan masalah yang mungkin rumit untuk dipecahkan. Beberapa kasus sistem pakar sangatlah membantu dalam menghasilkan beberapa pilihan yang mungkin sangat banyak perbandinganya apabila dihitung secara algoritma.

\section{Forward Chaining}

Forward chaining bisa dikatakan sebagai strategi inference yang bermula dari sejumlah fakta yang diketahui. Pencarian dilakukan menggunakan rule yang premisnya cocok dengan fakta yang diketahui untuk memperoleh fakta baru dan melanjutkan proses hingga selesai dicapai atau sudah tidak ada lagi rule yang premisnya cocok dengan fakta yang diketahui maupun fakta yang diperoleh.

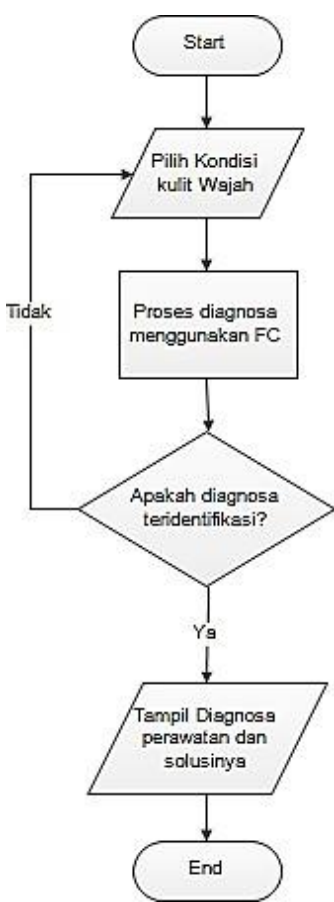

Gambar 1. Flowchart Forward Chaining

\section{Blok Diagram Sistem}

Menggambarkan hubungan antara elemen utama dari sistem pakar dalam identifikasi jenis kulit wajah manusia untuk menentukan perawatan facial. 

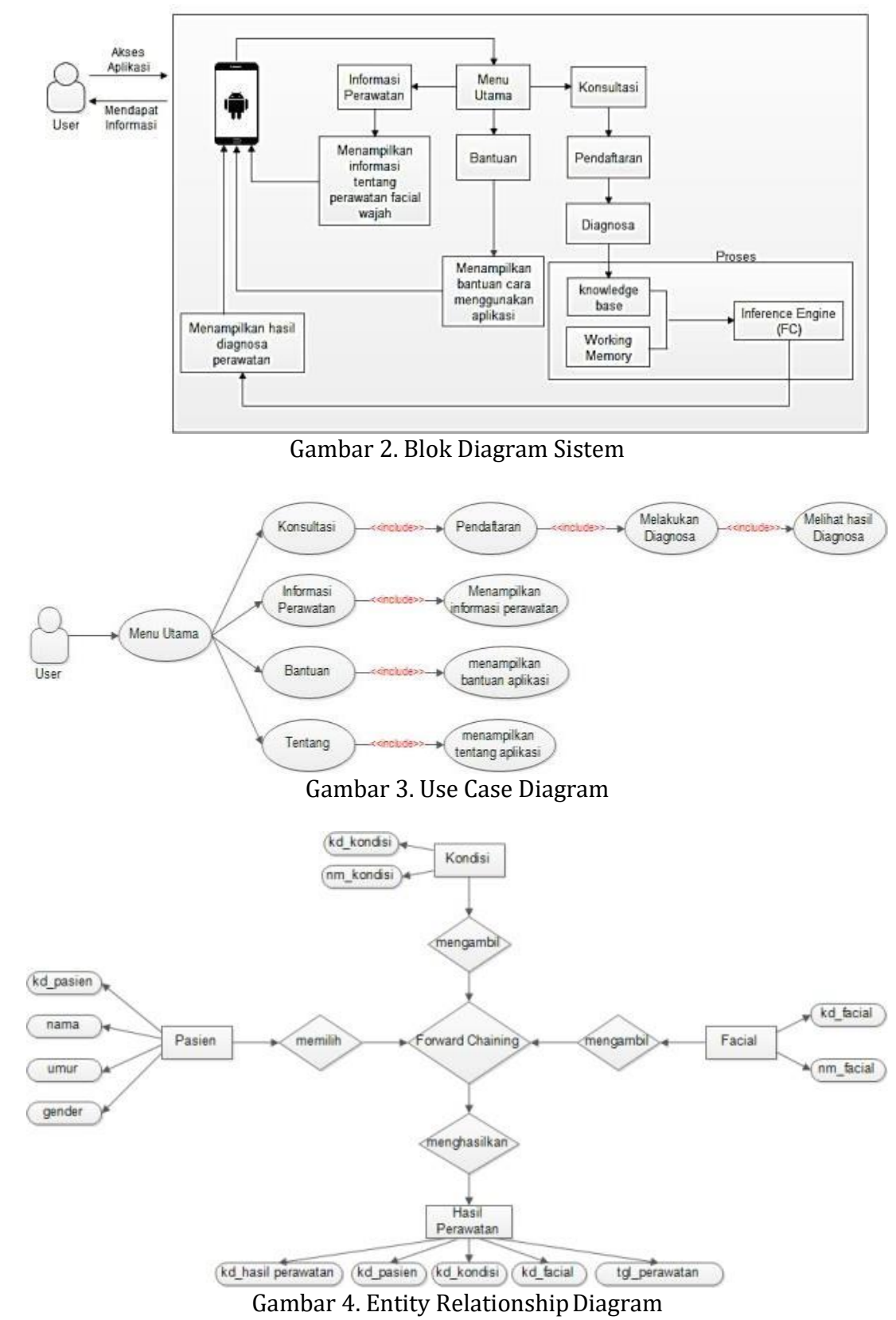

\section{Use Case Diagram}

Menggambarkan proses interaksi dan jenis interaksi antara pengguna dengan sistem.

\section{Entity Relationship Diagram}

ERD menggambarkan isi data yang disimpan dari sebuah sistem yang perancangan inferensi menjadi hal yang paling penting.

\section{IMPLEMENTASI DAN PEMBAHASAN}

\section{Tampilan Awal Program}

Tampilan awal program adalah halaman awal perawatan dari aplikasi android sebelum melakukan konsultasi. Berikut adalah tampilan yang menjelaskan bagaimana sistem berkerja dan disertai dengan print screen setiap tampilan beserta penjelasan dari tiap-tiap menu Konsultasi, Informasi Perawatan, Bantuan, Tentang dan Exit.

\section{Tampilan Konsultasi}

Pada gambar 6 menu Konsultasi, user harus melakukan pendaftaran perawatan facial kecantikan dengan mengisi nama, umur dan jenis kelamin.

\section{Tampilan Diagnosa}

Halaman Diagnosa pada gambar 7 user melakukan diagnosa kondisi kulit wajah dengan menjawab pertanyaan dari pakar dengan data kondisi wajah.

\section{Tampilan Hasil Perawatan}

Pada gambar 8 Halaman Hasil Perawatan berisi nama, umur, jenis kelamin yang telah diisi 
user saat melakukan pendaftaran. Di halaman hasil perawatan muncul jenis perawatan facial.

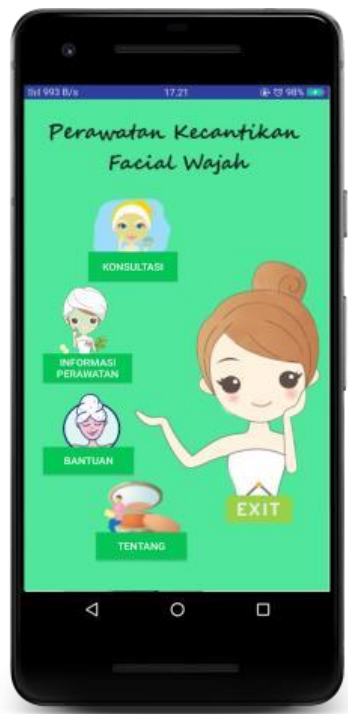

Gambar 5. Halaman Awal Perawatan

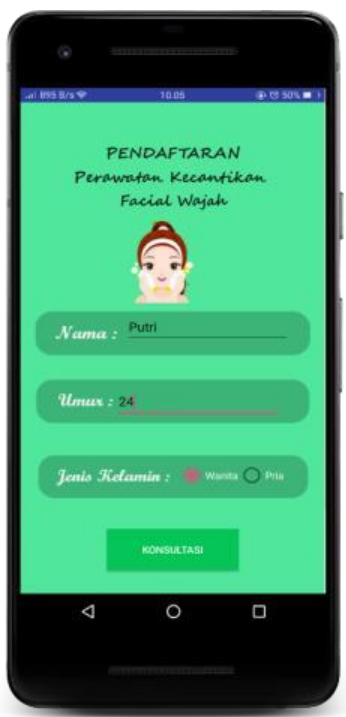

Gambar 6. Halaman Pendaftaran

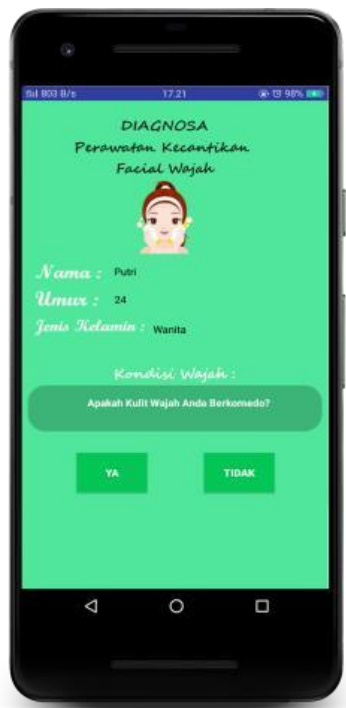

Gambar 7. Halaman Diagnosa

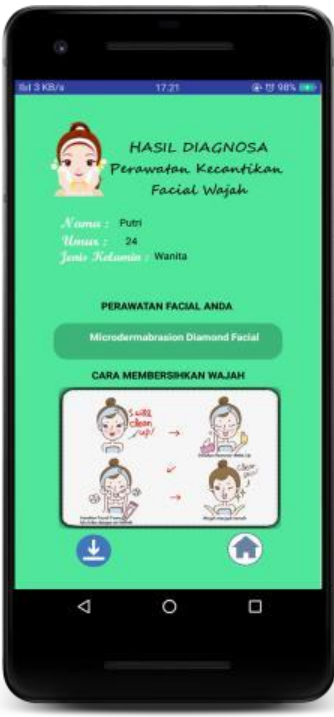

Gambar 8. Halaman Hasil Perawatan

\section{Tampilan Informasi Perawatan}

Pada Halaman Informasi Perawatan berisi tentang informasi jenis - jenis facial perawatan wajah disertai dengan gambar sesuai dengan jenis facialnya.

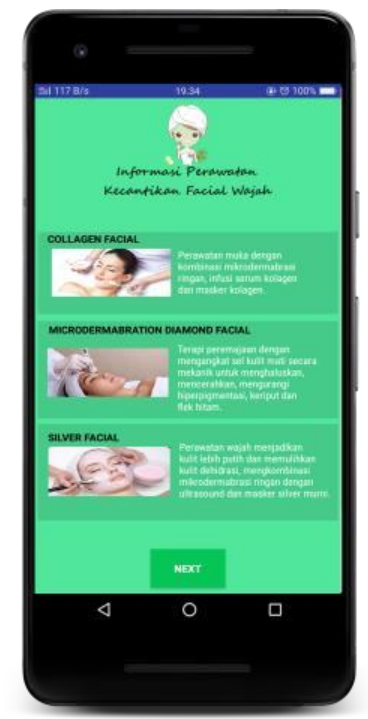

Gambar 9. Halaman Informasi Perawatan

Pada gambar 9 Halaman Informasi Perawatan Facial wajah berisi Informasi tentang beberapa jenis perawatan facial disertai gambarnya dan juga penjelasan yang membantu User mendapatkan informasi jenis perawatan lebih detail.

\section{Tampilan Bantuan}

Pada gambar 10 Halaman Bantuan berisi tentang cara menggunakan aplikasi Sistem Pakar Perawatan Facial Wajah dan menjelaskan tentang kegunaan setiap menu pada halaman perawatan sehingga memudahkan user untuk menggunakan aplikasinya. 


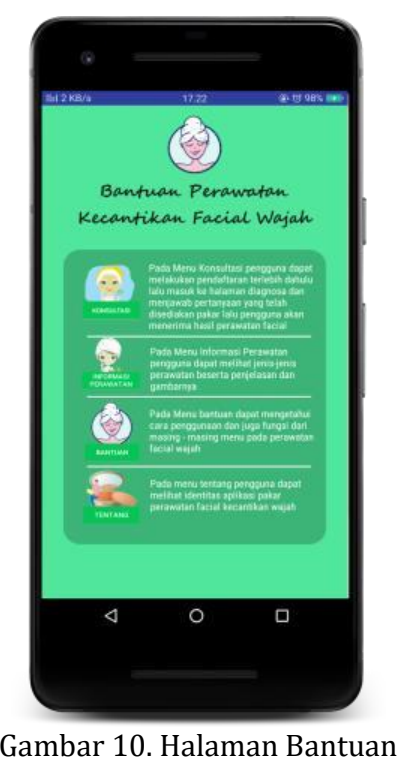

\section{Tampilan Tentang}

Pada gambar 11 berisi identitas aplikasi pakar perawatan facial wajah dan pengguna bisa mengirim email kepada admin/pakar untuk memberi komentar.

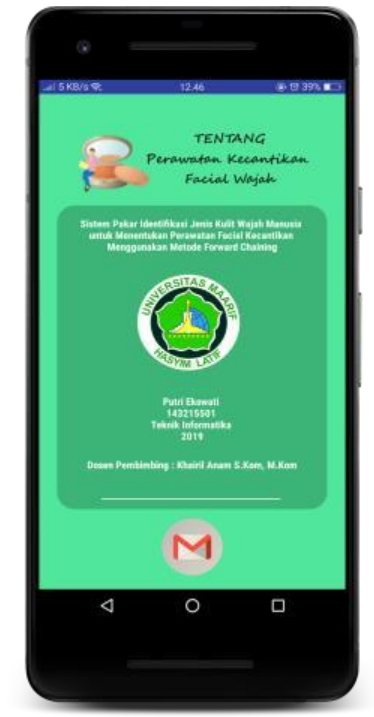

Gambar 11. Halaman Tentang

\section{Data Perawatan dan Kondisi Wajah}

Data perawatan facial dan kondisi kulit yang digunakan sebagai data input dan output pada aplikasi. Jenis Perawatan facial memiliki kode (F) sedangkan kondisi kulit wajah memiliki kode (K) pada tabel 1.

\section{Tabel Database Pasien}

Tabel Database Pasien ini disimpan di database firebase berisi kode pasien, nama, umur dan gender pada tabel 2 .

\section{Tabel Database Kondisi}

Tabel Database Kondisi ini berisi kode kondisi dan nama kondisi wajah pada tabel 3.
Tabel 1. Data Perawatan dan Kondisi Wajah

\begin{tabular}{c|l|c|l}
\hline $\begin{array}{c}\text { Kode } \\
\text { Facial }\end{array}$ & $\begin{array}{c}\text { Nama Perawatan } \\
\text { Facial }\end{array}$ & $\begin{array}{c}\text { Kode } \\
\text { Kondisi }\end{array}$ & \multicolumn{1}{|c}{ Kondisi Wajah } \\
\hline F1 & $\begin{array}{l}\text { Bio Acne Light } \\
\text { Therapy }\end{array}$ & K1 & Kulit Berjerawat \\
\hline F2 & IPL Acne facial & K1 K7 & $\begin{array}{l}\text { Kulit Berjerawat Kulit } \\
\text { Meradang }\end{array}$ \\
\hline F3 & $\begin{array}{l}\text { Bio Inflamed Light } \\
\text { Therapy }\end{array}$ & K1 K2 & $\begin{array}{l}\text { Kulit Berjerawat Kulit } \\
\text { Berminyak }\end{array}$ \\
\hline F4 & $\begin{array}{l}\text { Bio Rejuventati on } \\
\text { Light Therapy }\end{array}$ & K3 K5 & $\begin{array}{l}\text { Kulit Flek Hitam Kulit } \\
\text { Keriput }\end{array}$ \\
\hline F5 & $\begin{array}{l}\text { Microderma brasion } \\
\text { Diamond Facial }\end{array}$ & $\begin{array}{c}\text { K3 K5 } \\
\text { K6 }\end{array}$ & $\begin{array}{l}\text { Kulit Flek Hitam Kulit } \\
\text { Keriput Kulit Berkomedo }\end{array}$ \\
\hline F6 & Gold Facial & K8 & Kulit Kusam \\
\hline F7 & Silver Facial & K8 K4 & $\begin{array}{l}\text { Kulit Kusam Kulit } \\
\text { Kering }\end{array}$ \\
\hline F8 & Collagen Facial & K3 & Kulit Flek Hitam \\
\hline
\end{tabular}

Tabel 2. Database Pasien

\begin{tabular}{l|l|c|c|c}
\hline No & Field & Type & Width & Primary Key \\
\hline 1 & kd_pasien & Varchar & 3 & Ya \\
\hline 2 & nama & Varchar & 30 & Tidak \\
\hline 3 & umur & Integer & 2 & Tidak \\
\hline 4 & gender & Varchar & 6 & Tidak \\
\hline
\end{tabular}

Tabel 3. Database Kondisi

\begin{tabular}{l|l|c|c|c}
\hline No & Field & Type & Width & Primary Key \\
\hline 1 & kd_kondisi & Varchar & 3 & Ya \\
\hline 2 & nm_kondisi & Varchar & 30 & Tidak \\
\hline
\end{tabular}

\section{Tabel Database Facial}

Tabel Database Facial ini berisi kode facial dan nama facial wajah bisa dilihat pada tabel 4 .

Tabel 4. Database Facial

\begin{tabular}{|c|c|c|c|c|}
\hline Data & $\begin{array}{c}\text { Kondisi Kulit } \\
\text { Wajah }\end{array}$ & Diagnosa Dokter & Output Sistem & Ket \\
\hline D1 & $\begin{array}{l}\text { - Kusam } \\
\text { - Kering }\end{array}$ & Silver Facial & Silver Facial & Seruai \\
\hline D2 & - Kusam & Gold Facial & Gold Facial & Sesuai \\
\hline D3 & - Berjerawat & $\begin{array}{l}\text { Bio Acne Light } \\
\text { Therapy }\end{array}$ & $\begin{array}{l}\text { Bio Acne Light } \\
\text { Therapy }\end{array}$ & Seruai \\
\hline D4 & Flek Hitam & Collagen Facial & Collazen Factal & Sesua \\
\hline D5 & $\begin{array}{l}\text { - Berjerawat } \\
\text { - Meradang }\end{array}$ & IPL Acre Facial & IPL Acne Facial & Sesuai \\
\hline D6 & $\begin{array}{l}\text { - Berjerawat } \\
\text { - Meradang }\end{array}$ & IPL Acre Facial & IPL Acae Facial & Serua: \\
\hline D7 & $\begin{array}{l}\text { - Bejerawat } \\
\text { - Berminyak }\end{array}$ & $\begin{array}{l}\text { Bio Inflamed Light } \\
\text { Therapy }\end{array}$ & $\begin{array}{l}\text { Bio Influmed Light } \\
\text { Therapy }\end{array}$ & Seruai \\
\hline D8 & $\begin{array}{l}\text { - Flek Hitam } \\
\text { - Keriput } \\
\text { - Bekkomedo }\end{array}$ & $\begin{array}{c}\text { Microdenmabration } \\
\text { Diamond Facial }\end{array}$ & $\begin{array}{l}\text { Microdermabration } \\
\text { Diamond Facial }\end{array}$ & Seruzi \\
\hline D9 & $\begin{array}{l}\text { - Kusam } \\
\text { - Kering } \\
\end{array}$ & Silver Facial & Silver Facial & Sesuzi \\
\hline D10 & $\begin{array}{l}\text { Flek Hitam } \\
\text { Keriput }\end{array}$ & $\begin{array}{c}\text { Bio Rejuventation } \\
\text { Light Therapy }\end{array}$ & $\begin{array}{c}\text { Bio Rejuventation } \\
\text { Light Therapy }\end{array}$ & Sestaxi \\
\hline
\end{tabular}

\section{Tabel Database Hasil Perawatan}

Tabel Database Hasil Perawatan ini berisi kode hasil perawatan, kode pasien, kode kondisi, kode facial dan tanggal perawatan pada tabel 5 . 
Tabel 5. Database Hasil Perawatan

\begin{tabular}{r|l|c|c|c}
\hline No & Field & Type & Width & Primary Key \\
\hline 1 & kd_hasil perawatan & Varchar & 3 & Ya \\
\hline 2 & kd_pasien & Varchar & 3 & Tidak \\
\hline 3 & kd_kondisi & Varchar & 3 & Tidak \\
\hline 4 & kd_facial & Varchar & 3 & Tidak \\
\hline 5 & tgl_perawat an & Date & 15 & Tidak \\
\hline
\end{tabular}

\section{Uji Coba Program}

Uji coba program ini berdasarkan kriteria kebenaran input dan output aplikasi perawatan facial wajah. Hasil Uji keakuratan merupakan uji coba program yang dilakukan oleh user yaitu mahasiswa UMAHA Sidoarjo yang mengambil Tugas Akhir pada tahun 2019/2020 untuk menguji sistem. Uji coba dilakukan kepada 10 orang untuk mencoba melakukan konsultasi perawatan sesuai dengan kondisi wajahnya. Berikut hasil akurasi dari uji coba program aplikasi Sistem Pakar Identifikasi Jenis Kulit Wajah Manusia untuk Menetukan Perawatan Facial Kecantikan pada tabel 6.

Tabel 6. Data Akurasi Hasil Uji Coba

\begin{tabular}{l|c|c|l|l}
\hline No & Field & Type & Width & Primary Key \\
\hline 1 & kd_facial & Varchar & 3 & Ya \\
\hline 2 & nm_facial & Varchar & 30 & Tidak \\
\hline
\end{tabular}

\section{PENUTUP}

Dengan adanya program aplikasi sistem pakar ini sangat mempermudah dalam menyelesaikan permasalahan kulit wajah seseorang jika ingin melakukan perawatan facial kecantikan. Perancangan sistem pakar ini dibuat berbasis Android tentunya lebih praktis dan akan lebih memudahkan pengguna dalam mendiagnosa jenis kulit wajahnya tanpa harus mengantri dan menunggu konsultasi dengan dokter ataupun mendadak dokter sedang tidak bisa bertugas karena aplikasi ini seperti layaknya seorang pakar/dokter.

Program aplikasi sistem pakar dalam identifikasi kondisi jenis kulit wajah manusia untuk menentukan perawatan facial kecantikan ini juga perlu dikembangkan dengan kemajuan teknologi lebih lanjut, bisa menggunakan kamera secara langsung untuk mengidentifikasi kondisi wajah jadi langsung otomatis terdeteksi jenis kulit dan perawatan facial wajah serta juga perlu dikembangkan jenis perawatan facialnya sesuai dengan alat-alat kecantikan terbaru.

\section{DAFTAR PUSTAKA}

[1] Marimin, "Struktur dan Aplikasi Sistem Pakar Manajemen Pembangunan," vol. 1, no. 1, pp. 21-27, 1992.
[2] I. Russari, "Sistem Pakar Diagnosa Penyakit Batu Ginjal Menggunakan Teorema Bayes," Jurikom (Jurnal Ris. Komputer), vol. 3, no. 1, 2016.

[3] R. Gustikasari and S. Winiarti, "Aplikasi Sistem Pakar Penentuan Perawatan Kecantikan Berbasis Web (Studi Kasus: Pamella Salon YOGYAKARTA)," J. Sarj. Tek. Inform., vol. 1, no. 2, 2013.

[4] D. T. Wiyanti and E. W. Agustin, "Sistem Pakar Diagnosa Kulit untuk Menentukan Kosmetik Perawatan Wajah dengan Metode Certainty Factor dan Fuzzy Logic," in Seminar Nasional Ilmu Komputer (SNIK 2016), 2016.

[5] R. Amin, "Sistem Pakar Online Penentuan Ras Kucing dan Cara Perawatannya," Teknik Informatika - Fakultas Teknik - Universitas Muhammadiyah Purwokerto, 2017.

[6] F. Riandari, "Sistem Pakar Mendiagnosa Penyakit Kulit Wajah Menggunakan Metode Certainty Factor," J. Mantik Penusa, vol. 1, no. 2, 2017. 
P Ekowati / Ubiquitous: Computers and its Applications Journal, Vol. 3, No. 2, Desember 2020, 113-118 